Running head: COMMUNITY SUPPORT SERVICES

\title{
Getting Out There: Community Support Services for People with Intellectual and Developmental Disabilities in Medicaid HCBS Waivers
}

\author{
Carli Friedman, \& Natasha A. Spassiani
}

Inclusion, in press

Corresponding Author:

Carli Friedman, $\mathrm{PhD}$

Email: cfried6@uic.edu

Disability and Human Development

University of Illinois at Chicago

1640 W. Roosevelt Road, M/C 626

Chicago, IL, 60608, USA

Natasha A Spassiani, PhD, Assistant Professor, School of Education, Trinity College Dublin, the University of Dublin, Dublin 2, Ireland; spassian@tcd.ie

Acknowledgments:

Funds for this project were provided by a subcontract from the State of States in Developmental Disabilities project at the University of Colorado, School of Medicine. The State of State in Developmental Disabilities project is funded by the Administration on Developmental Disabilities in the U.S. Department of Health and Human Services (HHS). Research reported in this publication was also supported by the U.S. HHS, Administration for Community Living (ACL), National Institute on Disability, Independent Living, and Rehabilitation Research (NIDILRR) Grant \# 90AR5023. The content is solely the responsibility of the authors and does not necessarily represent the official views of the HHS and you should not assume endorsement by the Federal Government. 


\begin{abstract}
Despite an increased number of community-based services, people with intellectual and developmental disabilities (IDD) continue to struggle with meaningful community participation, and often feel they are not valued community members. This study examined how community support services, which support physical placement and community integration, were allocated in Medicaid 1915(c) HCBS waivers, the largest provider of long-term services and supports for people with IDD in the United States. Community support services totaled \$447.5 million of projected funding in fiscal year 2014. While community transition services funded expenses required to establish a basic household for the initial transition, community integration services promoted a successful community placement by utilizing natural supports and developing skills necessary to maintain community integration.
\end{abstract}

Keywords: Intellectual and developmental disabilities; Medicaid Home and Community Based Services waivers; community living; community integration 


\section{Getting Out There: Community Support Services for People with Intellectual and Developmental Disabilities in Medicaid HCBS Waivers}

Historically, people with intellectual and developmental disabilities (IDD) were forced into institutions where they were often neglected and unlawfully segregated. Because of worsening conditions, class action litigation required sweeping reform of institutions while setting standards of care for people with disabilities that often required deinstitutionalization. Research has since demonstrated in contrast to institutional placement, community living comes with many benefits, including increased choice and self-determination, greater participation, improved adaptive skills, and increased satisfaction (Larson, Lakin, \& Hill, 2013).

After peaking in 1967 (U.S. Department of Health, Education, and Welfare, 1972) depopulation of institutional settings has resulted in the closure of 174 public institutions for people with IDD in 43 states (Braddock et al., 2015). In addition to this trend, the United States Supreme Court Olmstead v. L.C. Decision (1999) also significantly impacted deinstitutionalization by requiring states provide services in the most integrated setting possible. The Olmstead decision required states to implement and expand services and supports to assist people with IDD in community living. As a result of these large changes, between 1977 and 2007 there was a 70\% decrease in physical institutional living for people with IDD (Rizzolo, Friedman, Luklinski, \& Braddock, 2013).

In $2013,66 \%$ of the $\$ 47.77$ billion of Medicaid spending for people with IDD was allocated for Medicaid Home and Community Based Services (HCBS) 1915(c) waivers, making them the largest providers of long-term services and supports for people with IDD in the community (Braddock et al., 2015; Rizzolo et al., 2013). HCBS 1915(c) waivers allow states to provide services in integrated community based settings by 'waiving' the main provisions of the 
Social Security Act (U.S. Department of Health and Human Services, 2000). This allows states to provide services more customized to fit the needs of certain populations, such as people with IDD. Since their creation HCBS waiver implementation has grown exponentially because of the preferences of people with IDD, improved outcomes, and the cost effectiveness (Hemp, Braddock, \& King, 2014; Larson \& Lakin, 1989; Larson, Lakin, \& Hill, 2013; Lakin, Larson, \& Kim, 2011; Mansell \& Beadle-Brown, 2004).

The aim of all HCBS waivers is community integration, which involves four components: 1) accessible and adequate accommodations located within the community; 2) access to a range of accommodations that are offered to the general population; 3 ) the right to choose where, how, and with whom they live; and, 4) the appropriate supports and services required for people with IDD to successfully participate within the community (Mansell \& Beadle-Brown, 2010). Services can be crucial for a proper community placement especially as people with IDD may have few possessions when exiting institutions. For example, Lulinski et al. (2014)'s evaluation of a large institution closing in Illinois found many consumers with IDD arrived at their new community homes with very few belongings, often in trash bags. Moreover, a number of participants were cited for actually being given other consumers belongings upon deinstitutionalization (Lulinski et al., 2014). If people with IDD are to successfully transition to the community it is important they have a suitable environment that is adequately furnished and clean. In fact, the Center for Medicaid and CHIP Services (2015) encourages states to provide community transition services in their HCBS 1915(c) waivers because "providing housingrelated activities and services facilitates community integration and is cost effective" (p. 1).

However, services for the initial transition are not enough to ensure successful community placements. Despite an increased number of community-based services offered, 
people with IDD continue to struggle with meaningful community participation, and often do not feel they are valued community members (Bratt \& Johnston, 1988; Forrester-Jones et al., 2002; Hammel et al., 2008; Marks \& Heller, 2003). As a result, Cullen et al. (1995) suggests people with IDD have merely become physically relocated into the community and not meaningfully integrated in and engaged with the community. Thus it is important for community integration services to not only provide physical integration but also facilitate social, cultural, and economic participation.

As community integration for people with IDD is dependent on service provisions (Cummins \& Lau, 2003) it is important to examine what types of community support services states deliver to ensure they are providing people with IDD the necessary tools to build successful community placements. Thus, the aim of this study is to examine how community support services are allocated in the largest funding system of long-term services and supports (LTSS) for people with IDD in the United States, Medicaid 1915(c) HCBS waivers. National comparisons across HCBS waivers are necessary due to large variation across state waiver programs (Friedman, Lulinksi, \& Rizzolo, 2015). To do so, fiscal year (FY) 2014 HCBS waiver applications for people with IDD providing community transition and integration services were compared to determine service utilization and expenditure projections. We also explored reimbursement rates, and service provision per participant. Finally, community support definitions were compared to determine trends, including how different types of community support services were defined and what was provided. In detailing utilization the purpose of the study is to explore the infrastructure Medicaid HCBS waivers put forth for supporting and promoting the successful community placements of people with IDD.

\section{Method}


As they are the most prevalent funding mechanism for the LTSS of people with IDD (Rizzolo et al., 2013) this study focused specifically on Medicaid HCBS 1915(c) waivers. State waiver applications were obtained from the Centers for Medicare and Medicaid (CMS) Medicaid.gov website over a 24-month period (June 2013 to June 2015). In doing so, waivers for populations other than intellectual disability (ID), "mental retardation" (MR), developmental disability (DD), and/or autism (ASD) were excluded. (Although outdated, MR remains a necessary search term because a number of waivers continue to use it (Friedman, in press).) No age limitations were imposed. See figure 1 for detailed tree of methodology. Waivers include plans for three to five years of services; waivers that did not include fiscal year (FY) 2014 were excluded. Although this was typically the states' FY (July 1, 2013 to June 30, 2014), a number of states used the federal FY (October 1, 2013 to September 30, 2014) and others used the 2014 calendar year (January to December). However, for consistency FY is used throughout this article. In total we collected 110 FY 2014 HCBS 1915(c) waivers for people with IDD from 45 states and the District of Columbia. States not included in this study either did not have a HCBS 1915(c) waiver for people with IDD or did not have a FY 14 HCBS waiver for people with IDD. As part of CMS requirements all waivers are required to describe: CMS assurances and requirements; levels of care; waiver administration and operation; participant access and eligibility; participant services, including limitations and restrictions; service planning and delivery; participation direction of services; participant rights; participant safeguards; quality improvement strategies; financial accountability; and cost-neutrality demonstrations (Disabled and Elderly Health Programs Group, Center for Medicaid and State Operations, Centers for Medicare and Medicaid Services, \& Department of Health and Human Services, 2015). This 
information was used to organize services into a taxonomy according to Rizzolo et al.'s FY 2010 HCBS taxonomy that was specifically tailored to IDD waivers (see figure 1).

After services were organized into taxonomy categories we were able to examine community support services further in depth. Although the CMS HCBS technical guide (Disabled and Elderly Health Programs Group, Center for Medicaid and State Operations, Centers for Medicare and Medicaid Services, \& Department of Health and Human Services, 2015) provides guidance to states on core service definitions they are able to adapt or modify definitions as they see fit (Rizzolo et al., 2013). For this reason, waivers' definitions of community support service were first qualitatively analyzed using grounded theory (Merriam, 2009) to determine themes, including different types of community support services and what was provided within these services. Community support service expenditure data was then quantitatively analyzed to determine service expenditures and utilization, including projected spending, projected number of users served, reimbursement rates, projected spending per participant, and annual service provision per participant.

\section{Findings}

\section{Service Definitions}

Services to aid people with IDD's access to the community - community support services - fell into two categories: community transition services; and, community integration services. Community transition services are generally one-time non-recurring set-up expenses to assist individuals transitioning from an institution, developmental center, or nursing facility to their own homes (rented, leased, owned, or agency operated) where they were responsible for their living expenses. Community transition services fund expenses required to establish a basic household, including obtaining and securing an adequate living environment and ensuring health 
and safety needs. This often included a combination of furnishings, household items, and set-up services necessary to support a successful transition. Community transition services could generally be utilized for security deposits to obtain a lease, and set-up fees or deposits for utilities such as electricity, heat, and water. They typically also included health and safety services such as pest control, allergen services, and cleaning prior to occupancy. Community transition services could be used for moving expenses as well as essential household furnishings such as furniture, window coverings, kitchen supplies, and linens. A number of waivers also allowed community transition services to be used to set up home accessibility adaptations. Many waivers also clarified that any items purchased through community transition services become the property of the waiver participant, even if the person moves to another residence.

Community transition services often also came with a number of restrictions and exclusions. Many waivers only allowed these services when the expenses could not be met from other sources, including having the person with IDD pay for the services themselves. For example, Massachusetts Intensive Supports Waiver's 'Transitional Assistance Services' explained,

“...Transitional Services are furnished only to the extent that they are reasonable and necessary as determined through the service plan development process, clearly identified in the service plan and the person is unable to meet such expense or when the services cannot be obtained from other sources."

As with the service described above, waivers generally also required services be reasonable and necessary. As such, recreational household appliances, televisions, cable, and DVD players were typically excluded. Also excluded from these particular services were monthly rental or mortgage expenses, and regular utility charges. 
Community integration services are services that aid people with IDD's access to the community while guiding them with coordination supports, and problem solving. Community integration services aid the access to and development of natural supports "while utilizing the community as a learning environment" (Colorado's Supported Living Services Waiver). This included supporting the person with IDD in developing, retaining, or improving skills to attend social events, recreational activities, and volunteering. Other examples included, "skills related to independent functioning, self advocacy, socialization, community participation, personal and financial responsibility, and other skills related to optimal well-being as defined in the Person Centered Plan of Care" (Kentucky's Michelle P. Waiver). Many services also provided lessons on the relationship building skills necessary to develop social networks.

In addition to aiding with social access community integration services were also aimed at supports coordination and problem solving. In doing so, many services offered community guides or specialists to help people with IDD navigate the community. They helped people with IDD adjust to community life by providing direct assistance with tasks like household maintenance, assistance with self-administered medications, and developing a routine. They also helped participants integrate into the community by teaching them skills such as those related to using public transportation, making appointments, and participating in recreation. It should be noted that many waivers required community guide services be unique from support coordination services, residential services, and/or day habilitation services.

\section{Service Expenditures}

Our analysis of 110 HCBS IDD waivers revealed 53 waivers (48.18\%) from 30 states and the District of Columbia provided community support through 99 different services in FY 2014. In FY 2014, \$447.5 million of funding was projected for community support services for 
approximately 52,000 participants. Of that $\$ 447.5$ million, $\$ 8.78$ million was projected for community transition services (2,892 participants) while $\$ 438.8$ million was projected for community integration services (49,073 participants). See table 2 . On average community support services projected spending $\$ 4.5$ million per service; however total projected spending varied widely by service from $\$ 186$ for Missouri Children with DD Waiver's “Group Community Integration" service (2 participants) to $\$ 58.4$ million for Georgia Comprehensive Supports Waiver Program's “Community Access Group” service (5,218 participants). Table 3 details total projected spending on community support services by state.

Spending per participant also ranged widely. While an average of $\$ 5,953$ was projected per participant for community support services, this differed significantly between community integration and transition services (Table 2). Projected spending per participant for community transition services ranged from $\$ 75$ (Texas Home and Community-based Services Program) to $\$ 7,324$ (Wisconsin Self Directed Support Waiver). Community integration services ranged from $\$ 93$ (Missouri Children with DD Waiver) to $\$ 57,672$ (Wisconsin Long Term Support DD Waiver). Figure 2 details this spread.

In their waivers states detailed service provision rates; community supports services were paid by hourly, daily, weekly, monthly, and one-time transition rates. One large difference between community transition and community integration services was the way rates were provided. While the majority of community transition services ( $n=32$ services, $88.9 \%$ of community transition services) were paid by a bulk rate for a one-time transition (figure 3 ), the majority of community integration services ( $n=53$ services, $84.1 \%$ of community integration services) were paid by hourly rate (Table 2). Figure 3 details projected one-time transition rates for community transition services. 
The average projected hourly rate for community integration services was $\$ 28.48$; figure 4 details how hourly rates ranged. Three services provided community integration services by daily rate, projecting $\$ 134.33$ per day, one service provided weekly projecting $\$ 838.13$ per week, and two services provided monthly rates projecting an average of $\$ 450.81$ per month. Finally, four services paid by unit, projecting an average of $\$ 25$ per unit.

While the majority of participants projected to receive community transition services would only receive one-time transitions, for those community integration services that paid by hourly rate the average participant was projected to receive 333 hours of community integration services per year (figure 5). Meanwhile, daily rate community integration services projected 160 days of services per year, weekly rate services 52 weeks of services per year, and monthly rate services 10.5 months of services per year. Finally, although community transition services that allocated by unit were for one-time transitions, community integration services that allocated by unit provided on average 200 units per year.

\section{Discussion}

Almost half of Medicaid HCBS 1915(c) waivers (48\%) were utilizing community support services to aid people with IDD's initial move to the community, and continued community placement in FY 2014. As such community transition services were used in HCBS waivers to fund expenses required to establish a basic household. In addition to securing an adequate living environment, this included ensuring the space was clean and furnishing the environment with essential household items such as furniture, bedding, and kitchen supplies. Many waivers also provided community integration services in order to promote a successful community placement by utilizing natural supports and developing the skills necessary to maintain community integration. 
In FY 2014 community support services projected spending \$447.5 million for 51,965 participants through 99 different services. Although $\$ 447.5$ million of funding was projected for community support services, this was actually a very small proportion (1.4\%) of total HCBS waiver funding for people with IDD in FY 2014 (Friedman \& Rizzolo, 2015). We also found a large variability across states and services regarding total projected spending, reimbursement rates, annual services provisions, and spending per participant. For example, average projected spending per participant ranged from $\$ 75$ to $\$ 57,672$ per participant.

One reason for this large variance was the difference between community transition services and community integration services. Almost 50 times the funding was projected for community integration services than community transition services. On average, community integration services also had higher spending per participant and provided users with more units of service in a year than community transition services, which tended to be one-time services. However, even within community transition and community integration services there was significant variance across projected spending, spending per participant, reimbursement rates, and service provision per participant. Although this variance may appear extreme, it tends to be a common theme across HCBS waiver services for people with IDD. Our examination of other HCBS waiver services (i.e., day habilitation services; dental services; electronic monitoring services; family support services; mental/behavioral health services; occupational therapy services; personal care services; prevocational services; supported employment services; and, transportation services (Friedman, 2016; Friedman, in press; Friedman \& Caldwell, in preparation; Friedman \& Rizzolo, under review; 2014; 2016a; 2016b; Friedman et al., 2015; Friedman, Rizzolo, \& Schindler, 2014; Friedman \& Van Puymbrouck, in press)) has unearthed similar trends. As CMS does not require states to detail reasoning behind these decisions there is 
no way to determine why there are such large differences across states; future studies should examine the reasoning behind states' decisions regarding allocation and utilization.

When interpreting our findings it should be noted that HCBS waiver applications are based on projections made to the federal government rather than actual spending. However, they are a reasonably accurate proxy of waiver services because they are based on previous years' HCBS 1915(c) waiver utilization data. Moreover, Rizzolo et al. (2013) found HCBS waiver projections to be very similar to actual expenditure analyses by Irvin (2011) and Braddock et al. (2015). However, one limitation of projected data is service provision alone is not necessarily a good metric of success. Simply because community support services are provided does not necessarily mean the users with IDD are successfully integrated into the community. Thus, we suggest future research examine how successful these waiver services are at promoting meaningful social integration. For example, one useful avenue would be to explore how well community support services foster critical independent living skills such as problem solving, decision-making skills, and relationship building. As research by McMichael-Peirce (2015) found facilities providing community integration did not truly understand community integration, we also suggest future research about integration outcomes be person-centered and designed with people with IDD.

\section{Implications for Practice and Policy in Promoting Inclusion}

As people with IDD are the main stakeholders we would also suggest an expansion of the implementation of person-centered and self-directed community support services (National Council on Disability, 2013). We found a small number of waivers specified the need to promote self-determination and empowerment of people with IDD. For example, North Carolina Innovations waiver explained, "the purpose of this service is to promote self-determination, 
increase independence and enhance the participant's ability to interact with and contribute to his or her local community.” Similarly, Georgia's New Options and Comprehensive Supports waivers stressed the importance of participant-direction stating, "Community Guide services are designed to empower participants to define and direct their own services and supports." As Medicaid HCBS waivers are increasingly being used to support community LTSS states must ensure these waivers are being utilized to fund community needs that are important and relevant to people with IDD. For example, adults with IDD in Myers, Ager, Kerr, and Myles’ (1998) study noted the importance of having access to a telephone to keep in contact with their family and friends; in our study we found many waivers allowed community transition services to be used to set-up telephones.

Despite the benefits of community support services, a number of services required Medicaid HCBS waivers to be a 'payer of last resort;' the implications of which can be problematic because of the reliance on informal caregivers. One assumption often made regarding the success of transitioning people with IDD to the community is that informal caregivers will be available. This is especially pertinent due to limited support services provided by states. Informal caregivers do play an important role; in fact, the United States LTSS system is largely upheld by informal caregiving (Gallanis \& Gittler, 2012; Kunkel, Applebaum, \& Nelson, 2003). Although reliance on informal caregivers allows many programs to be more cost effective, within the current service system it is problematic and unsustainable to design services to be dependent on family members and other informal caregivers who already face an increased burden (Rizzolo, Hemp, \& Braddock, 2006). This dependence on informal supports has important implications for policymakers and state Medicaid directors, who are trying to provide LTSS for people with IDD while also limiting spending. As such, in addition to expanding 
community support services, we suggest Medicaid HCBS waivers not be considered a payer of last resort for these services. Integrating people with IDD into the community requires independent living skills that most individuals would not have had the opportunity to develop while living in institutions; thus, in order to ensure integration policies need to address this need to ensure successful, meaningful, and sustainable community living can be achieved by people with IDD.

There are many benefits to community living; it is significantly more cost effective than institutional living and people with IDD also find it preferable to institutional living (Braddock et al., 2015; Hemp, Braddock, \& King, 2014; Larson \& Lakin, 1989, 2012; Lakin, Larson, \& Kim, 2011; Mansell \& Beadle-Brown, 2004). The ultimate aim of community support services we examined was to establish and build a successful community environment for people with IDD. Community support services are critical to ensure people with IDD are integrated into the community rather than simply physically located in the community. Successful community placements hinge on this distinction. 


\section{References}

Braddock, D., Hemp, R., Rizzolo, M. C., Tanis, E. S., Haffer, L., \& Wu, J. (2015). The state of the states in intellectual and developmental disabilities: Emerging from the great recession (10 $0^{\text {th }}$ edition). Washington, DC: The American Association on Intellectual and Developmental Disabilities.

Bratt, A., \& Johnston, R. (1988). Changes in life style for young adults with profound handicaps following discharge from hospital care into a "second generation" housing project. Mental Handicap Research, 1(1), 49-74.

Center for Medicaid and CHIP Services. (2015, June 26). Coverage of housing-related activities and services for individuals with disabilities CMCS Informational Bulletin. Baltimore, MD: Center for Medicaid and CHIP Services.

Cummins, R. A., \& Lau, A. L. (2003). Community integration or community exposure? A review and discussion in relation to people with an intellectual disability. Journal of Applied Research in Intellectual Disabilities, 16(2), 145-157.

Disabled and Elderly Health Programs Group, Center for Medicaid and State Operations, Centers for Medicare and Medicaid Services, \& Department of Health and Human Services. (2015, January). Application for a $§ 1915(c)$ Home and Community-Based Waiver [Version 3.5]: Instructions, technical guide, and review criteria. from http://www.medicaid.gov/Medicaid-CHIP-Program-Information/ByTopics/Waivers/Downloads/Technical-Guidance.pdf

Forrester-Jones, R., Carpenter, J., Cambridge, P., Tate, A., Hallam, A., Knapp, M., \& Beecham, J. (2002). The quality of life of people 12 years after resettlement from long stay hospitals: Users' views on their living environment, daily activities and future aspirations. 
Disability \& Society, 17(7), 741-758.

Friedman, C. (2016). Day habilitation services in Medicaid Home and Community Based Services waivers. Research and Practice for Persons with Severe Disabilities. Online first, 1-12. http://dx.doi.org/10.1177/1540796916664337

Friedman, C. (in press). Outdated language: Use of 'mental retardation' in Medicaid HCBS waivers post-Rosa's law. Intellectual and Developmental Disabilities.

Friedman, C. \& Caldwell, K. (in preparation). Preparing for integrated community-based employment: Prevocational services for people with intellectual and developmental disabilities.

Friedman, C., Lulinski, A. \& Rizzolo, M. C. (2015). Mental/behavioral health services: Medicaid Home and Community Based Services 1915(c) waiver allocation for people with intellectual and developmental disabilities. Intellectual and Developmental Disabilities, 53(4), 257-270. http://dx.doi.org/10.1352/1934-9556-53.4.257

Friedman, C. \& Rizzolo, M. C. (2016). The state of transportation for people with intellectual and developmental disabilities in Medicaid Home and Community Based Services 1915(c) waivers. Journal of Disability Policy Studies. Online first. http://dx.doi.org/10.1177/1044207316644413

Friedman, C. \& Rizzolo, M. C. (2016). Un/Paid labor: Medicaid Home and Community Based Services waivers that pay family as personal care providers. Intellectual and Developmental Disabilities, 54(4), 233-244. http://dx.doi.org/10.1352/1934-9556$\underline{54.4 .233}$

Friedman, C. \& Rizzolo, M.C. (2015). 2014: An analysis of state-by-state HCBS Waivers for persons with intellectual disabilities. Chicago: University of Illinois at Chicago. 
Friedman, C., \& Rizzolo, M. C. (2014). Research brief: Services that support families in Medicaid HCBS waivers in fiscal year 2013. Boulder and Chicago: University of Colorado and University of Illinois at Chicago.

Friedman, C. \& Rizzolo, M. C. (under review). Electronic video monitoring to maintain community placements of people with intellectual and developmental disabilities.

Friedman, C. \& Rizzolo, M. C. (in press). “Get us real jobs:” Supported employment services for people with intellectual and developmental disabilities in Medicaid Home and Community Based Services waivers. Journal of Vocational Rehabilitation.

Friedman, C., Rizzolo, M. C., \& Schindler, A. (2014). Dental services: A nationwide study of Medicaid Home and Community-Based Services (HCBS) waiver service allocation. Inclusion, 2(1), 17-36. http://dx.doi.org/10.1352/2326-6988-2.1.17.

Friedman, C. \& VanPuymbrouck, L. (in press). Occupational therapy in Medicaid Home and Community Based Services waivers. American Journal of Occupational Therapy.

Gallanis, T. P., \& Gittler, J. (2012). Family Caregiving and the Law of Succession: A Proposal. University of Michigan Journal of Law Reform, 45(4), 13-12.

Hammel, J., Jones, R., Smith, J., Sanford, J., Bodine, C., \& Johnson, M. (2008). Environmental barriers and supports to the health, function, and participation of people with developmental and intellectual disabilities: report from the State of the Science in Aging with Developmental Disabilities Conference. Disability and health journal, 1(3), 143149.

Hemp, R., Braddock, D., \& King, M. (2014). Community-based Medicaid funding for people with intellectual and developmental disabilities. National Conference of State Legislatures LegisBrief, 22, 1-2. 
Irvin, C. (2011, September). Applying the HCBS taxonomy to person-level Medicaid data. Paper presented at the National Home and Community-Based Services Conference, Washington, DS.

Kunkel, S., Applebaum, R., \& Nelson, I. (2003). For love and money: Paying family caregivers. Generations, 27(4), 74-80.

Larson, S. A., \& Lakin, K. C. (1989). Deinstitutionalization of persons with mental retardation: Behavioral outcomes. Journal of the Association for Persons With Severe Handicaps, 14(4), 324-332.

Larson, S.A., Lakin, K.C., \& Hill, S.L. (2013). Behavioral outcomes of moving from institutional to community living for people with intellectual and developmental disabilities: U.S. studies from 1977 to 2010. Research \& Practice for Persons with Severe Disabilities, 37(4), 235-246. doi: 10.2511/027494813805327287

Lakin, K. C., Larson, S. A., \& Kim, S. (2011). Behavioral outcomes of deinstitutionalization for people with intellectual and/or developmental disabilities: Third decennial review of U.S. studies, 1977-2010 Policy Research Brief(Vol. 21): Research and Training Center on Community Living, Institute on Community Integration, University of Minnesota.

Lulinski, A. et al. (2014). An evaluation of the Jacksonville Developmental Center closure: Part 1. Chicago: Institute on Disability and Human Development, University of Illinois at Chicago.

Mansell, J., \& Beadle-Brown, J. (2004). Person-centred planning or person-centred action? Policy and practice in intellectual disability services. Journal of Applied Research in Intellectual Disabilities, 17, 1-9.

Mansell, J., \& Beadle-Brown, J. (2010). Deinstitutionalisation and community living: position 
statement of the Comparative Policy and Practice Special Interest Research Group of the International Association for the Scientific Study of Intellectual Disabilities1. Journal of Intellectual Disability Research, 54(2), 104-112.

Marks, B. A., \& Heller, T. (2003). Bridging the equity gap: Health promotion for adults with intellectual and developmental disabilities. Nursing Clinics of North America, 38(2), 205228.

McMichael-Peirce, T. J. (2015). Is community integration understood by those charged with facilitating it? Journal of Christian Institute on Disability, 4(2), 41-73.

Merriam, S. B. (2009). Qualitative research: A guide to design and implementation. San Francisco, CA: Jossey-Bass.

Myers, F., Ager, A., Kerr, P., \& Myles, S. (1998). Outside looking in? Studies of the community integration of people with learning disabilities. Disability \& Society, 13(3), 389-413.

National Council on Disability. (2013). A progress report: "Strength in our differences". Washington, DC: National Council on Disability.

Olmstead v. LC, No. No. 98-536, 527581 (Supreme Court 1999).

Rizzolo, M. C., Friedman, C., Lulinski Norris, A., \& Braddock, D. (2013). Home and Community Based Services (HCBS) waivers: A nationwide study of the states. Intellectual and Developmental Disabilities, 51(1), 1-21. http://dx.doi.org/10.1352/19349556-51.01.001.

Rizzolo, M. C., Hemp, R., \& Braddock, D. (2006, February). Family support services in the United States. Policy Research Brief: University of Minnesota, 17(1), 1-12.

U.S. Department of Health and Human Services. (2000). Understanding Medicaid home and community services: A primer. Washington, DC: Author. 
U.S. Department of Health, Education, and Welfare. (1972). Mental retardation source book of the DHEW. Washington, DC: Author. 
Table 1. Differentiation Between Community Transition and Integration Services.

Table 1

Differentiation Between Community Transition and Integration Services

\begin{tabular}{lcc}
\hline Typically included features & $\begin{array}{c}\text { Community } \\
\text { transition } \\
\text { services }\end{array}$ & $\begin{array}{c}\text { Community } \\
\text { integration } \\
\text { services }\end{array}$ \\
\hline Set-up expenses & $\mathrm{X}$ & \\
Establish basic household & $\mathrm{X}$ & \\
Obtain and secure living environment & $\mathrm{X}$ & \\
Initial health and safety needs (eg pest control, cleaning) & $\mathrm{X}$ & \\
Initial household items (eg furnishings, kitchen supplies) & $\mathrm{X}$ & \\
Obtain lease or other set-up fees (eg electricity) & $\mathrm{X}$ & $\mathrm{X}$ \\
Moving expenses & $\mathrm{X}$ & $\mathrm{X}$ \\
Adjustment to community life (eg household maintenance, & & $\mathrm{X}$ \\
routine) & & $\mathrm{X}$ \\
Community skill development (eg public transportation) & & $\mathrm{X}$ \\
Development/improvement of social skills & & \\
Lessons on relationship building and aiding access to natural & & \\
supports & & \\
Guiding/support with problem solving & & \\
\hline
\end{tabular}


Table 2. Community Support Services Allocation (Projected).

Table 2

Community Support Services Allocation (Projected)

\begin{tabular}{|c|c|c|c|c|c|c|}
\hline & \multicolumn{3}{|c|}{ Total } & \multicolumn{3}{|c|}{ Average } \\
\hline & Combined & CTS & CIS & Combined & CTS & CIS \\
\hline Unduplicated participants & 51,965 & 2,892 & 49,073 & 525 & 80 & 779 \\
\hline Total projected spending & & & & & & \\
\hline (millions) & $\$ 447.54$ & $\$ 8.78$ & $\$ 438.76$ & $\$ 4.52$ & $\$ .24$ & $\$ 6.96$ \\
\hline Average spending per participant & & & & $\$ 5,953$ & $\$ 2,452$ & $\$ 7,954$ \\
\hline \multicolumn{7}{|l|}{ Average reimbursement rates } \\
\hline hourly & & & & $\$ 32$ & $\$ 73$ & $\$ 28$ \\
\hline daily & & & & $\$ 134$ & $\mathrm{n} / \mathrm{a}$ & $\$ 134$ \\
\hline weekly & & & & $\$ 838$ & $\mathrm{n} / \mathrm{a}$ & $\$ 838$ \\
\hline monthly & & & & $\$ 451$ & $\mathrm{n} / \mathrm{a}$ & $\$ 451$ \\
\hline each/unit/transition & & & & $\$ 2,026$ & $\$ 2,284$ & $\$ 25$ \\
\hline \multicolumn{7}{|l|}{ Average yearly service provision } \\
\hline hourly & & & & 310 & 15 & 333 \\
\hline daily & & & & 160 & $\mathrm{n} / \mathrm{a}$ & 160 \\
\hline weekly & & & & 52 & $\mathrm{n} / \mathrm{a}$ & 52 \\
\hline monthly & & & & 11 & $\mathrm{n} / \mathrm{a}$ & 11 \\
\hline each/unit/transition & & & & 26 & 1 & 200 \\
\hline
\end{tabular}

Note. CTS $=$ Community transition supports. CIS = Community integration services. 
Table 3. Projected Spending by State

Table 3

Projected Spending by State

\begin{tabular}{|c|c|c|c|c|}
\hline State & $\begin{array}{l}\text { Number of } \\
\text { waivers } \\
\text { providing } \\
\text { these services }\end{array}$ & $\begin{array}{c}\text { Projected } \\
\text { spending (in } \\
\text { thousands) }\end{array}$ & $\begin{array}{l}\text { Percent of } \\
\text { total } \\
\text { projected } \\
\text { HCBS IDD } \\
\text { spending }\end{array}$ & $\begin{array}{c}\text { Spending } \\
\text { per } \\
\text { capita } \\
\end{array}$ \\
\hline Alabama & 2 & $\$ 9.7$ & $0.003 \%$ & $\$ 0.002$ \\
\hline Arizona & 1 & $\$ 176.0$ & $0.08 \%$ & $\$ 0.03$ \\
\hline California & 1 & $\$ 42.6$ & $0.002 \%$ & $\$ 0.001$ \\
\hline Colorado & 2 & $\$ 11,442.7$ & $3.33 \%$ & $\$ 2.10$ \\
\hline Florida & 1 & $\$ 37.0$ & $8.87 \%$ & $\$ 0.002$ \\
\hline Georgia & 2 & $\$ 139,952.8$ & $26.21 \%$ & $\$ 13.70$ \\
\hline Idaho & 1 & $\$ 22,575.9$ & $11.44 \%$ & $\$ 13.64$ \\
\hline Indiana & 1 & $\$ 119.1$ & $0.02 \%$ & $\$ 0.01$ \\
\hline Kansas & 1 & $\$ 26,284.7$ & $6.60 \%$ & $\$ 9.03$ \\
\hline Kentucky & 2 & $\$ 74,225.2$ & $14.06 \%$ & $\$ 16.77$ \\
\hline Louisana & 2 & $\$ 124.3$ & $0.02 \%$ & $\$ 0.03$ \\
\hline Maine & 1 & $\$ 32,284.3$ & $10.66 \%$ & $\$ 24.29$ \\
\hline Maryland & 1 & $\$ 516.7$ & $0.06 \%$ & $\$ 0.09$ \\
\hline Massachusetts & 2 & $\$ 129.3$ & $0.01 \%$ & $\$ 0.02$ \\
\hline Minnesota & 1 & $\$ 22.5$ & $0.002 \%$ & $\$ 0.004$ \\
\hline Mississippi & 1 & $\$ 8.0$ & $0.01 \%$ & $\$ 0.003$ \\
\hline Missouri & 5 & $\$ 24,771.1$ & $4.77 \%$ & $\$ 4.07$ \\
\hline Montana & 1 & $\$ 32.5$ & $0.03 \%$ & $\$ 0.03$ \\
\hline $\begin{array}{l}\text { New } \\
\text { Hampshire }\end{array}$ & 1 & $\$ 3,882.3$ & $1.83 \%$ & $\$ 2.92$ \\
\hline New Mexico & 2 & $\$ 43,422.0$ & $14.84 \%$ & $\$ 20.82$ \\
\hline New York & 2 & $\$ 1,268.2$ & $0.02 \%$ & $\$ 0.06$ \\
\hline North Carolina & 2 & $\$ 30,182.0$ & $2.55 \%$ & $\$ 3.01$ \\
\hline Oregon & 1 & $\$ 8.7$ & $0.01 \%$ & $\$ 0.002$ \\
\hline Pennsylvania & 2 & $\$ 12,464.2$ & $0.60 \%$ & $\$ 0.97$ \\
\hline South Carolina & 2 & $\$ 13,249.2$ & $2.81 \%$ & $\$ 2.71$ \\
\hline Texas & 3 & $\$ 581.2$ & $0.05 \%$ & $\$ 0.02$ \\
\hline Utah & 1 & $\$ 5.8$ & $0.003 \%$ & $\$ 0.002$ \\
\hline Virginia & 2 & $\$ 552.0$ & $0.08 \%$ & $\$ 0.07$ \\
\hline Washington & 4 & $\$ 3,028.5$ & $0.57 \%$ & $\$ 0.42$ \\
\hline $\begin{array}{l}\text { Washington, } \\
\text { DC }\end{array}$ & 1 & $\$ 175.0$ & $0.10 \%$ & $\$ 0.26$ \\
\hline Wisconsin & 3 & $\$ 5,965.2$ & $0.50 \%$ & $\$ 1.03$ \\
\hline
\end{tabular}


Figure 1. Process for identification of included HCBS 1915(c) IDD community support services.

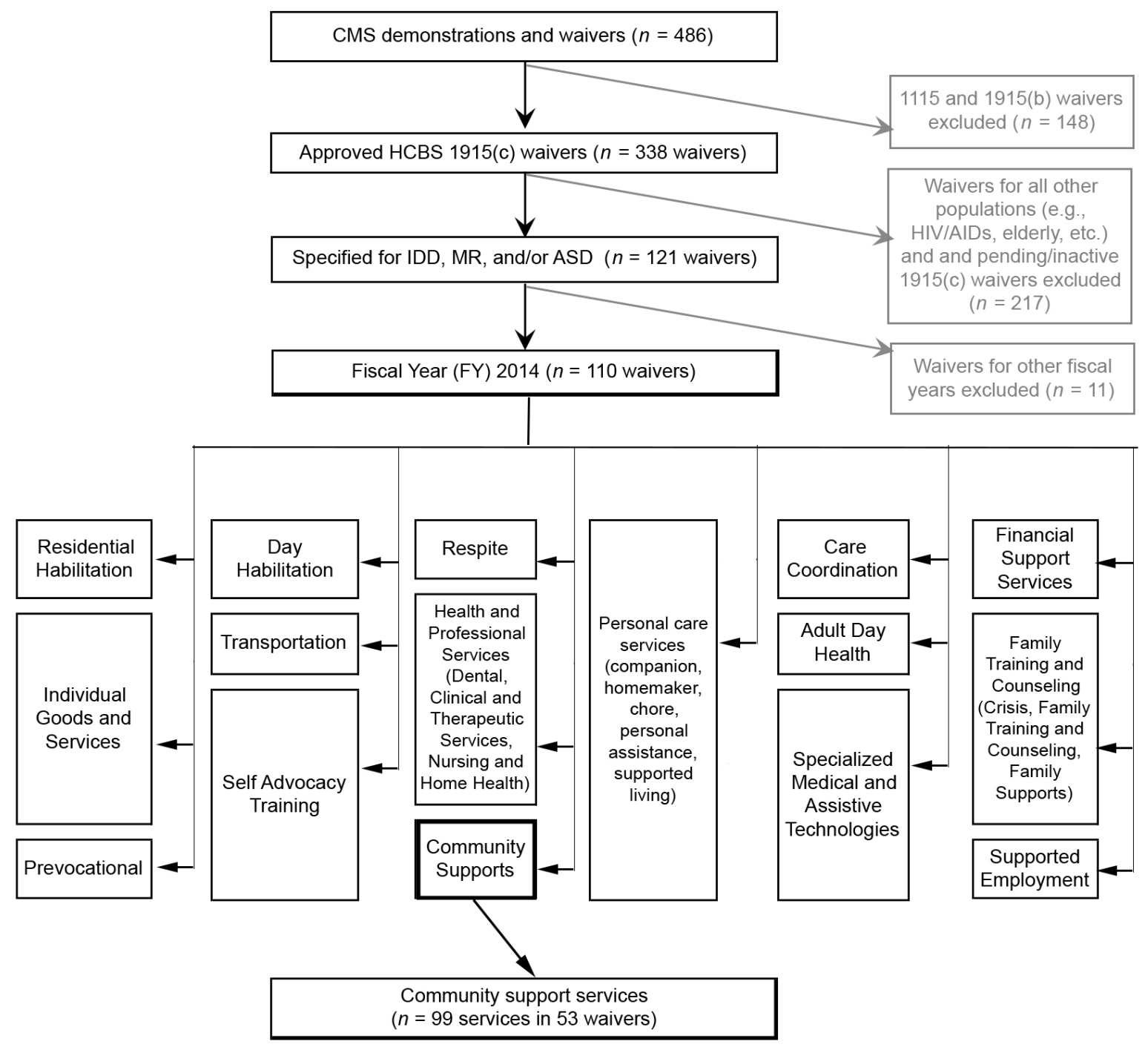


Figure 2. Projected spending per participant for community support services.
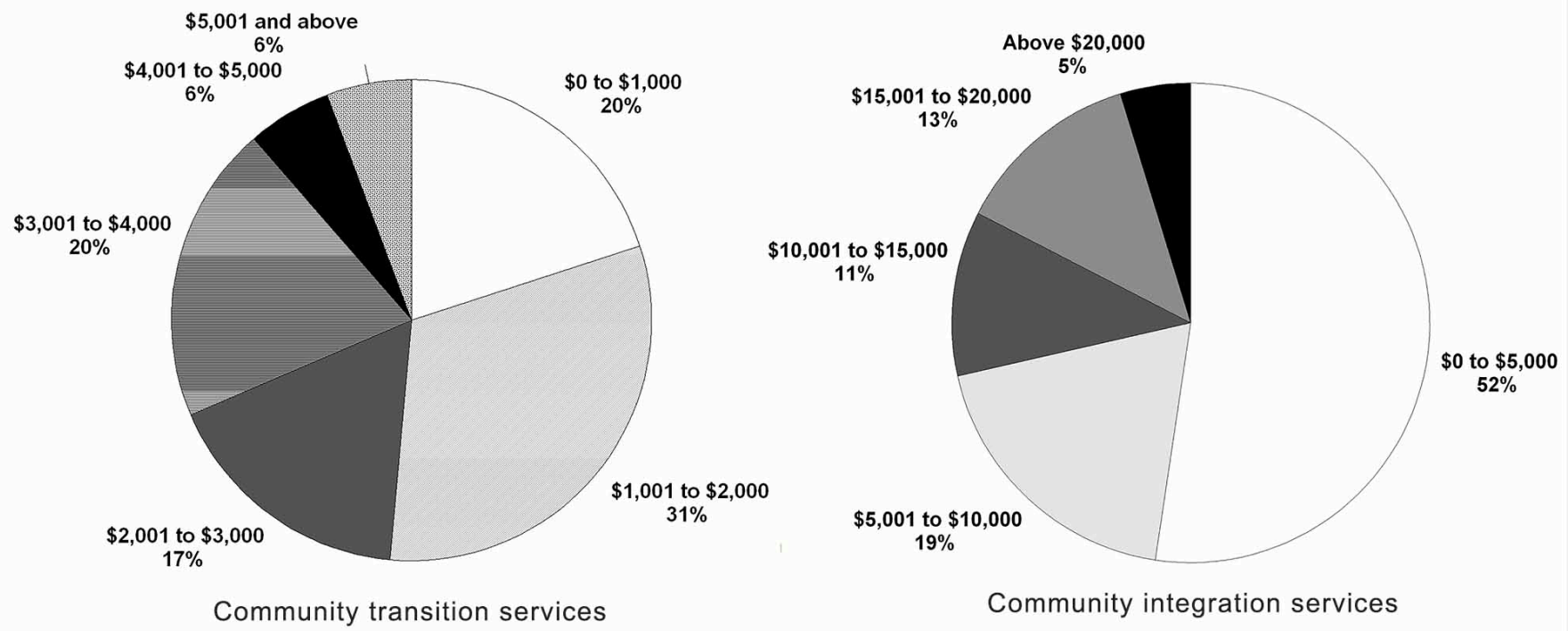
Figure 3. Average community transition service rates for a one-time transition.

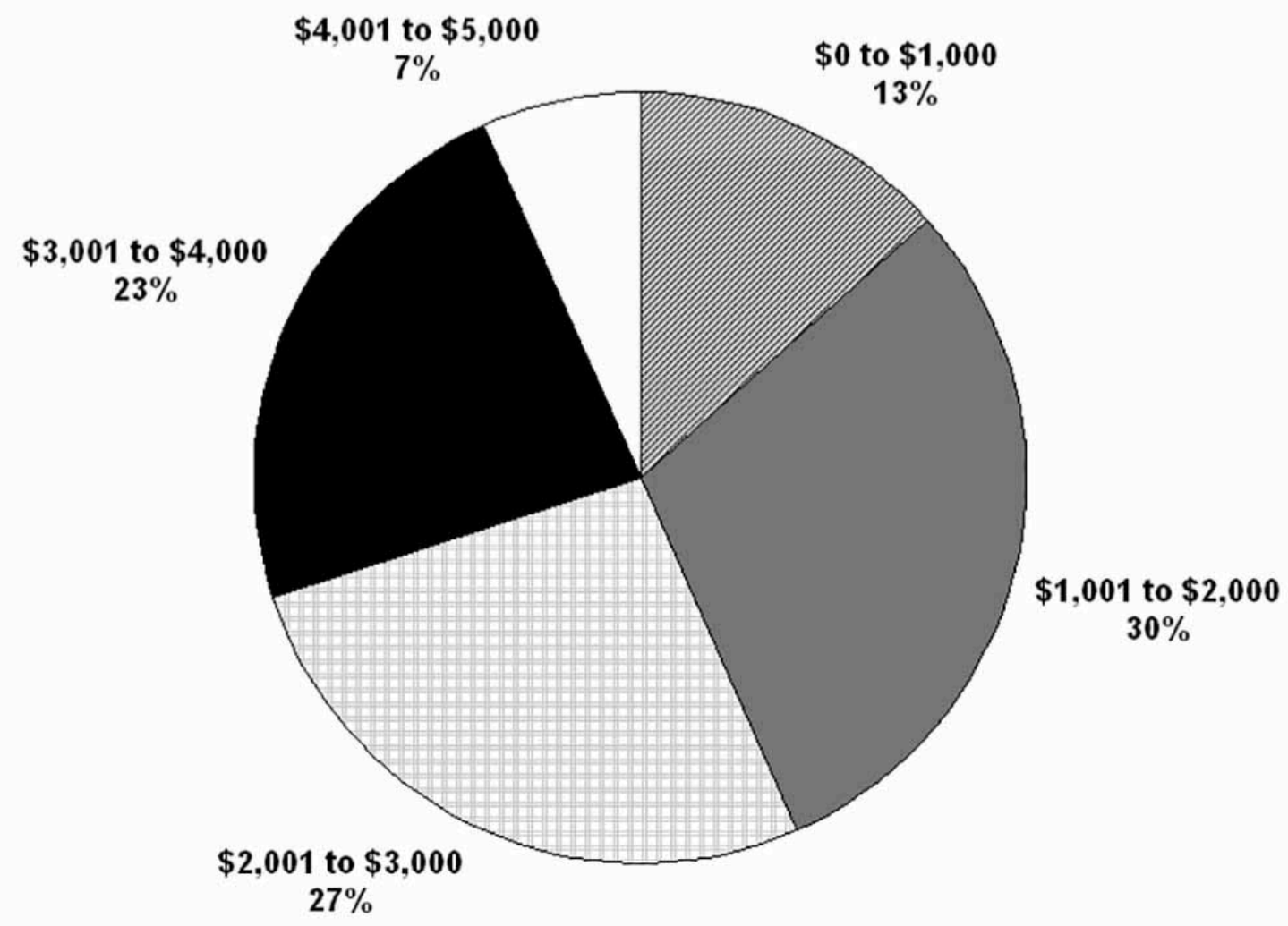


Figure 4. Projected hourly rates for community integration services.

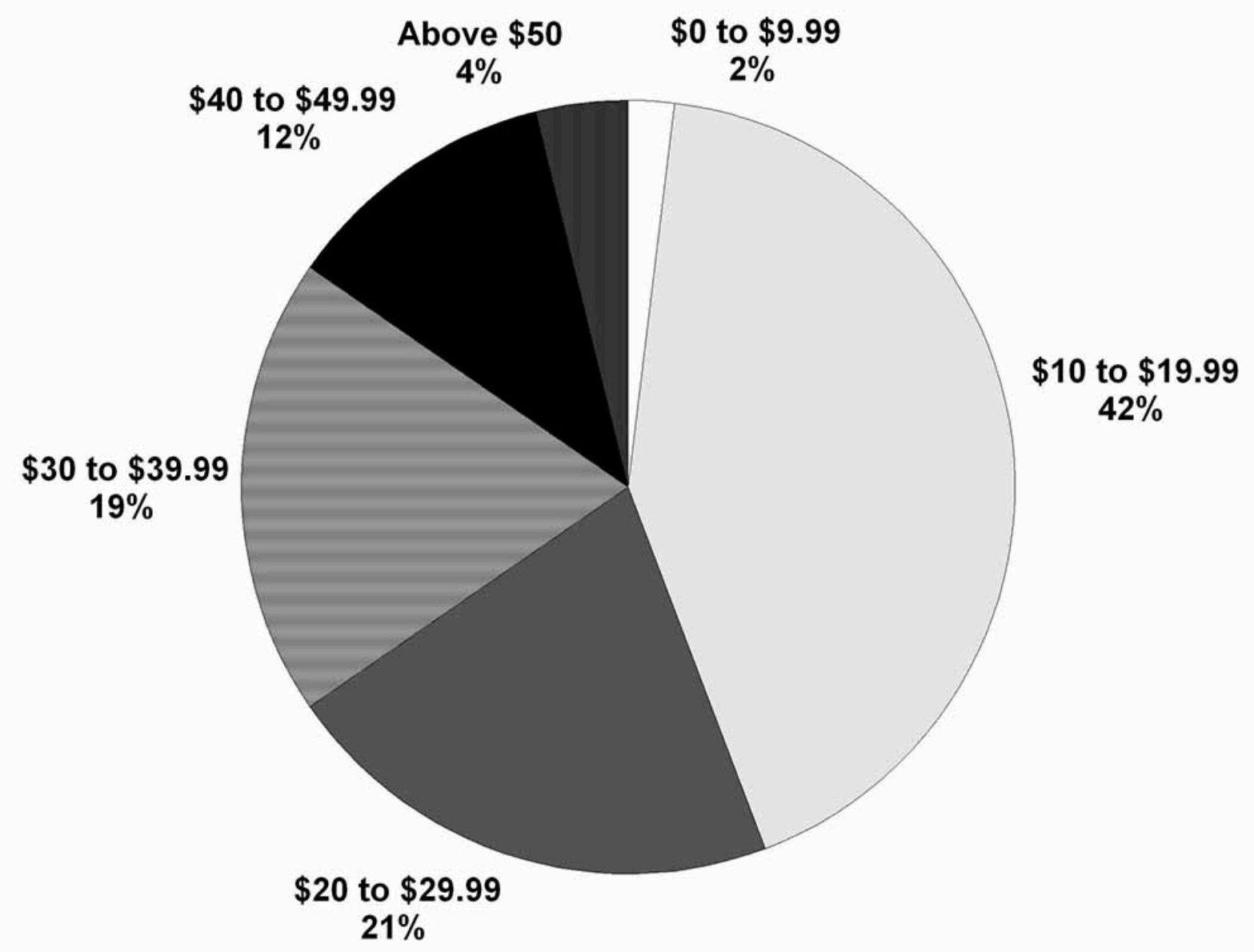


Figure 5. Hours of community integration services projected per participant annually.

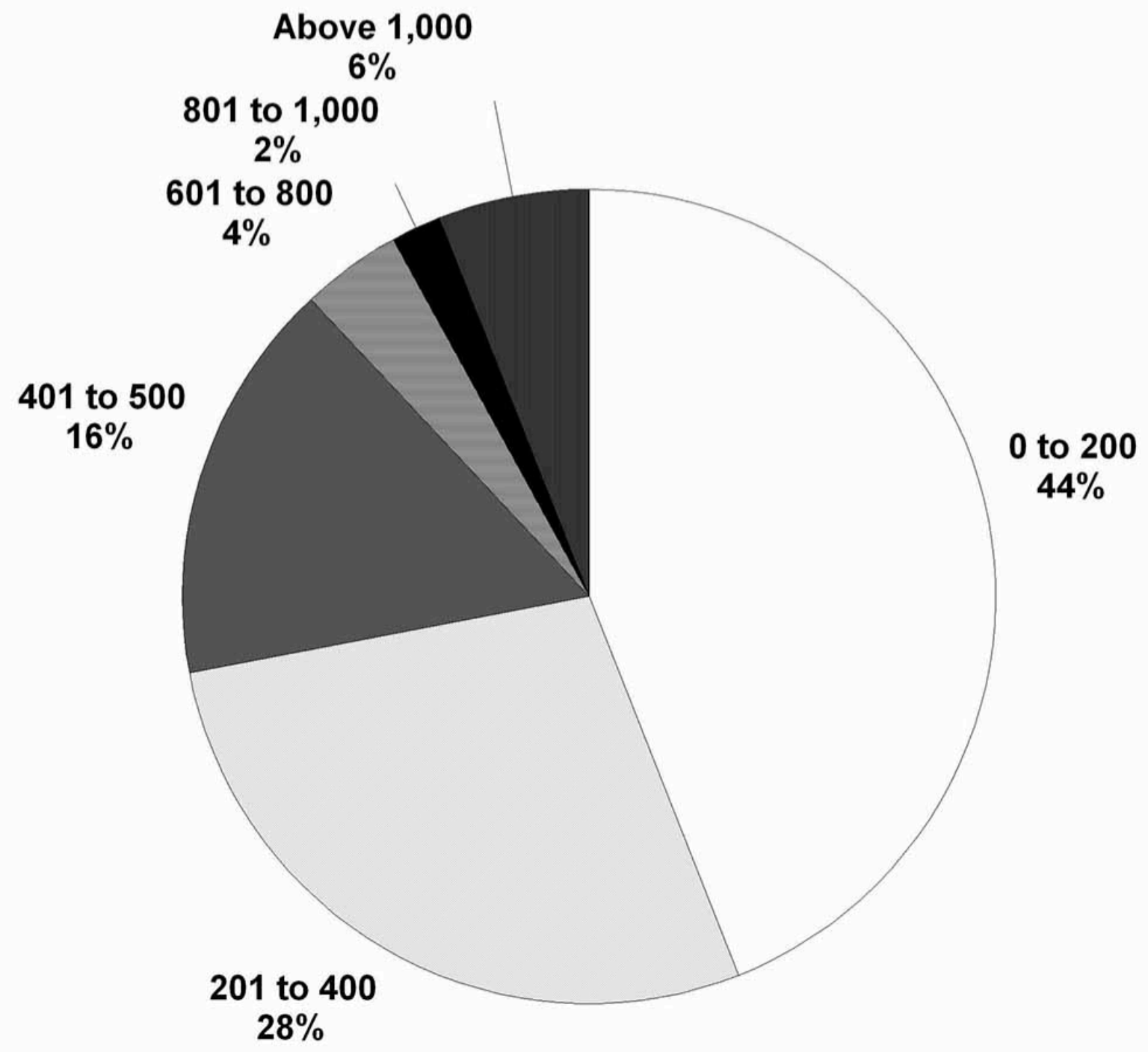

